\title{
CONSERVATION AND UTILIZATION OF THE BEAR RESOURCES IN CHINA
}

MA YIQING, Institute of Natural Resources, 25 Haping Road, Harbin, Heilongjiang 150040, Peoples Republic of China

Abstract: In China, a bear's fur, grease, gall, paw, meat, and other parts are highly valued. The bear has been an important game species since ancient times. However, in the past 100 years, bear habitat has been destroyed, and the number of bears has been declining because of unreasonable bunting methods, overharvest, and extensive deforestation. The result is that every subspecies of bear in China is now listed in the protected animal catalog, not only protected by national wildtife protection law, but also supervised by CITES. China formerly was one of the countries with the most abundant bear resources.

Int. Conf. Bear Res, and Manage, 9(1):157-159

\section{DISTRIBUTION OF BEAR RESOURCES}

Recent investigations indicate that there are 3 species and 10 subspecies of bears in China. Their distribution is shown in Figure 1 and Tabie 1.

\section{UTILIZATION OF BEAR RESOURCES}

There is a long history of utilization and hunting for bear resources in China, recorded in many historical documents. The "Li Ji Record," written in the third century B.C., says: "to deal with bears in hibernation, fire and smoke were used to dispel bears from dens, then they were kilfed, and their [fur], gall bladders, paws, etc. were taken." Because bear products have a high economic value, some government staff were assigned to manage the hunting of bears at that time. The winter hide of the bear, with its abundant hair, is treated and used as ornament, for fur garments, on mattresses, and as carpet. It has been regarded as a luxurious product from ancient times. In Chinese

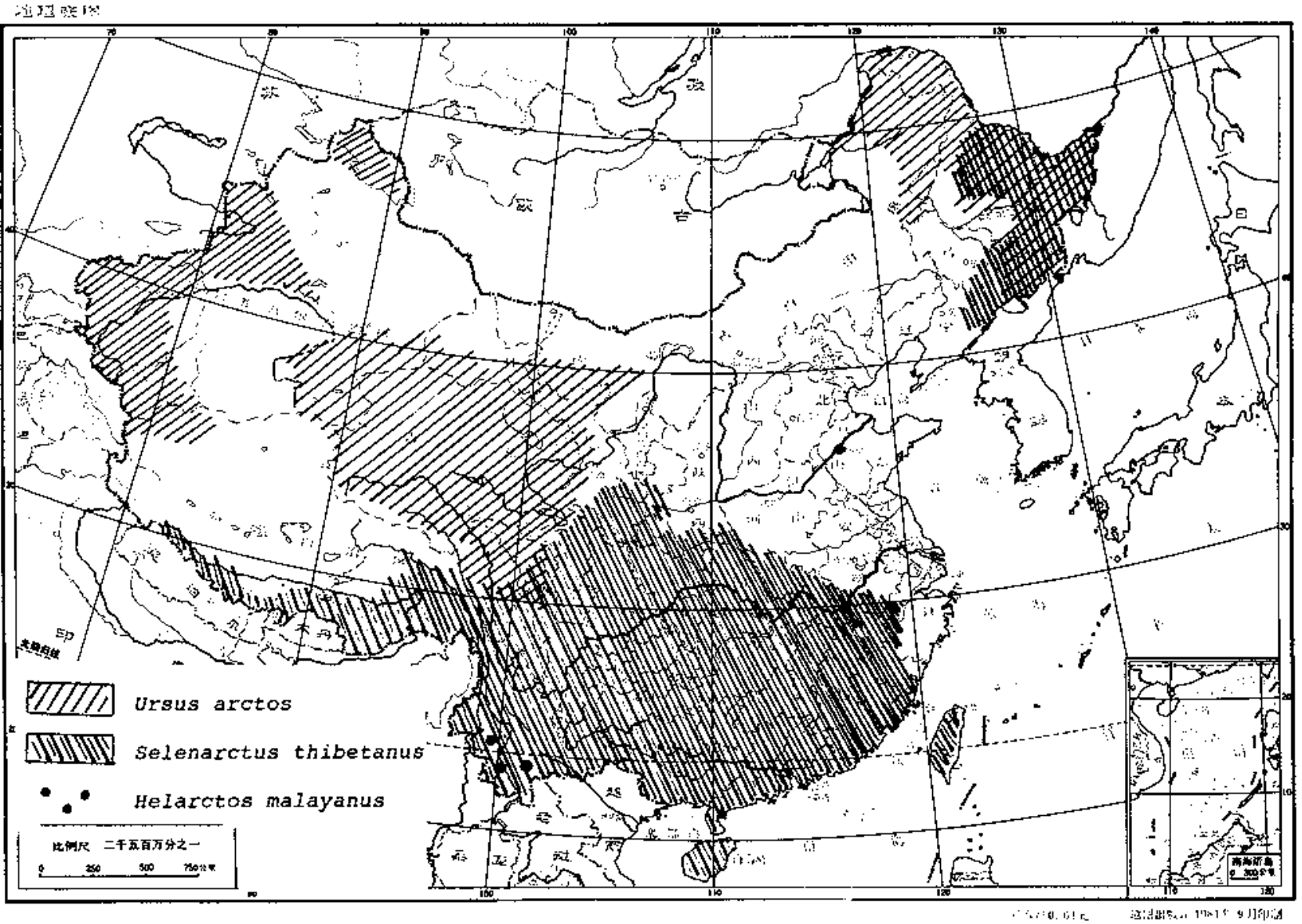

Fig. 1. The distribution of bear in China. 
Table 1. The distribution of bear subspecies in China.

\begin{tabular}{ll}
\hline Subspecies & Distribution area \\
\hline Brown Bear (Ursus arctos) & \\
U. a. arctos, Linnaeus 1758 & Altai Mountains \\
U. a. isabellina, Horsfield 1826 & Tianshan \& Qunlun Mountains \\
U. a. lasiotus, Gray 1867 & Northeastern China Region \\
U. a. pruinosus, Blyth 1853 & Qingzang Plateau
\end{tabular}

Black Bear (Selenarctos thibetanus)

S. t. thibetanus, G. Cuvier 1823

Southern Yunnan Province

S. $t$. formosanus, Swinhoe 1864

Taiwan \& Hainan Islands

S. t. laniger, Poccock 1932

Southern Xizang Aut. Region

S. t. mupinensis, Heude 1901

Southwest, Central \& South China

S. $t$. ussuricus, Heude 1901

Northeastern China Region

Sun Bear (Helarctos malayanus)

culture, bear paws have always been regarded as one of the "eight delicacies," and are eaten for health reasons and to prevent diseases.

Bear gall and grease are historically recognized medicines. Grease was used as the "best goods" for a long lifespan, but was often eaten to prevent hunger as recorded in the "Shen Nong Medicine," which was written in the Han Dynasty. Effective medical ingredients are ursodeoxycholic acid (C24H4004) and chenodeoxycholic acid (in the gall). Doctors using traditional Chinese medicine think that gall has medical qualities for the formation of antipyretic, brightening eyes, sedation, releasing poison, and so on. There are many different prescriptions used in various places.

Since 1985, when a process was developed in China for extracting gall from living bears, bears have been raised in captivity for the production of gall. There is about $2,000 \mathrm{~g}$ dry powder gall produced by each bear per year. This approach, using captive bears to produce gall, is seen as beneficial not only in the production of medical gall, but also to protect wild bear resources by decreasing hunting pressure on them by gall-hunters. As of the end of 1990, approximately 6,000 bears were in captivity in China. There are 27 big bear farms currently operating under agreements with the Administry of Health (Fig. 2).

\section{CONSERVATION OF BEAR RESOURCES}

Under Chinese law, the Malayan sun bear is listed as the first class of protected animal. The brown bear and black bear are listed under the second class in Conservation Law of Wildlife, which went into effect in March 1989. Bears are now legally protected, and hunting without approval of the administration department of the government will be punished according to the law.

For example, poachers who killed 26 bears in forest areas of Heilongjiang, paid high fines or received criminal sentencing. By the end of 1990, China had established 600 natural reserves with an area of 238,000 $\mathrm{km}^{2}$, occupying $2.47 \%$ of the whole country. Within these reserves, bears and their habitat are conserved.

\section{SUGGESTIONS}

The following management suggestions are offered: 1. China should enforce the protection law of wildlife seriously, and strengthen legal supervision of enforcement. China has joined the CITES. We should manage and conserve bear resources according to law.

2. Attention should be paid to ecological studies and protection measures. Sound ecological data are the basis of natural resource conservation. Excessive timber harvest, mining, and the construction of largescale engineering projects are affecting and reducing bear habitat. Better ecological studies will yield data and information needed for conservation strategy so as to better balance human needs with the needs 


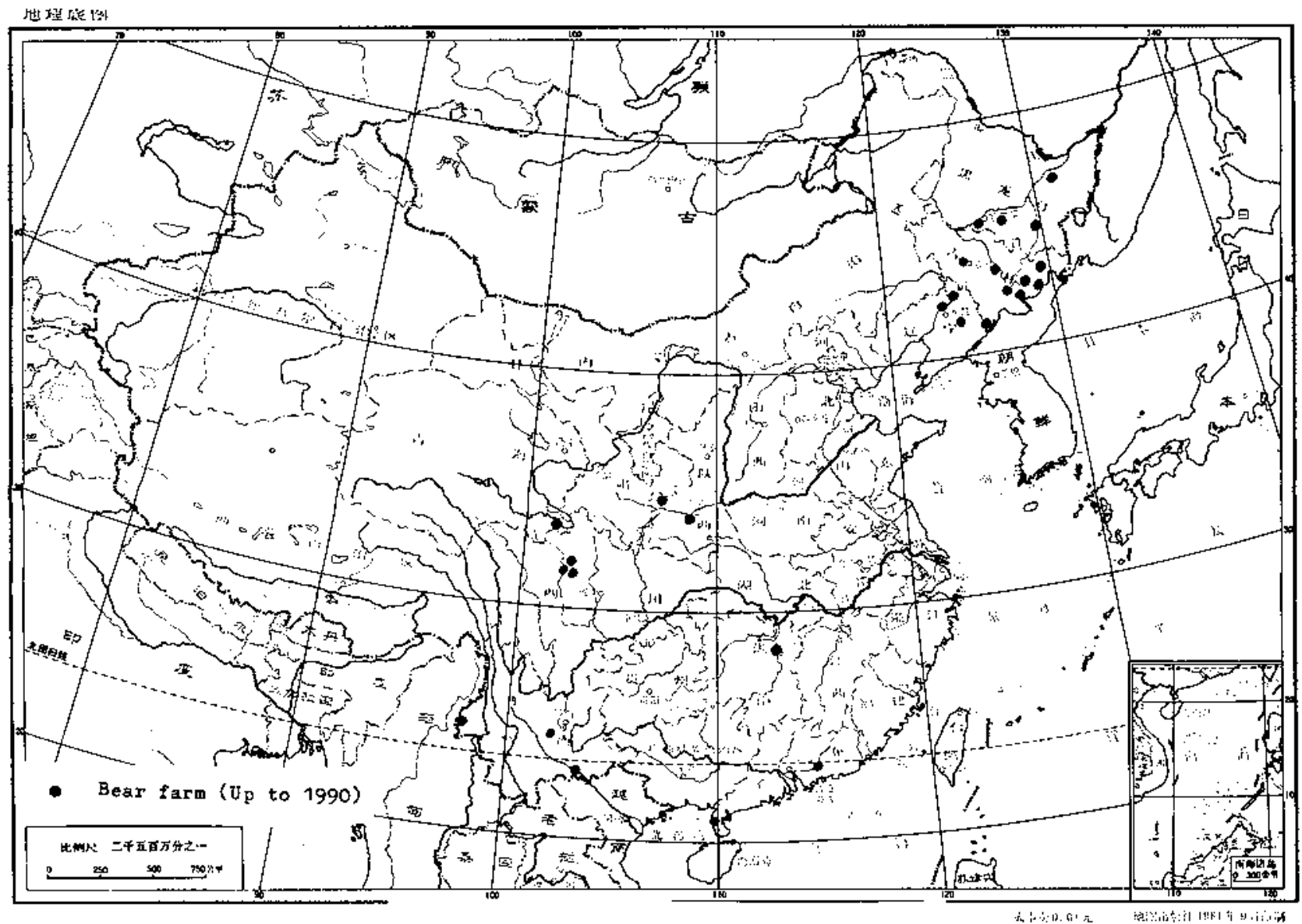

Fig. 2. Big bear farms in China (up to 1990).

of bears.

3. China, Japan, and Korea are now building large bear farms. Artificial breeding techniques and experimental bile removal in farmed bears should improve based on scientific research. This should result in improved ability to utilize the captive bear resources rationally,

4. China should heighten international cooperation in conservation. Bears, like other animal resources, are the property of all people, and more research and conservation of bear resources are necessary.

\section{BIBLIOGRAPHY}

PAOZHANG, K. 1990. A threatened wild animal in Taiwan-

Formosan black bear. Pages 70-75 in Proceedings of the First Eastern Asjatic Bear Conf. on Bear Biol. and Their Status.

YaotiNG, G., ET AL. 1987. Fauna Sinica. Mammalia. Vol. 8. Carnivora. Scientific Press. 378pp. (In Chinese with English summary.)

YINGXIANG, W. 1990. The distribution and protection of bears in Yunan Province, China. Pages 76-80 in Proceedings of the First Eastern Asiatic Bear Conf. on Bear Biol. and Their Status.

YlQING, M. 1981. Bears distribution in China. Acta Theriologica Sinica. 1(2):137-144. (In Chinese with English summary.)

- 1983. The status of bear in China. Acta Zoologica Fennca. 174:165-166.

1986. The bear's feature and its economic value.

Nat. Resour. Res. (4):26-30. (In Chinese.)

. 1990. The distribution of bears in Heilongjiang Province and changed in population density over a ten year period. Pages 81-84 in Proceedings of the First Eastern Asiatic Bear Conf. on Bear Biol. and Their Status.

ET AL. 1986. The mammals of Heilongiang Province. Heilongjiang Scientific and Technology Press. Pages 131-139. (In Chinese with English summary.) 